\title{
Strength, Carbon Footprint and Cost Considerations of Mortar Blends with High Volume Ground Granulated Blast Furnace Slag
}

\author{
Chiu Chuen Onn ${ }^{1, *}$, Kim Hung Mo ${ }^{1, *}{ }^{\mathbb{D}}$, Mohammed K. H. Radwan ${ }^{1} \mathbb{D}$, Wen Hong Liew ${ }^{1}$, \\ Chee Guan $\mathrm{Ng}^{2}$ and Sumiani Yusoff ${ }^{2}$ \\ 1 Department of Civil Engineering, Faculty of Engineering, University of Malaya, 50603 Kuala Lumpur, \\ Malaysia; eng.moh.rad@gmail.com (M.K.H.R.); wenhong.wh34@gmail.com (W.H.L.) \\ 2 Institute of Ocean and Earth Sciences, University of Malaya, IGS Building, No. C308, 50603 Kuala Lumpur, \\ Malaysia; cheeguan.ng@um.edu.my (C.G.N.); sumiani@um.edu.my (S.Y.) \\ * Correspondence: onnchiuchuen@um.edu.my (C.C.O.); khmo@um.edu.my (K.H.M.)
}

Received: 27 September 2019; Accepted: 27 November 2019; Published: 16 December 2019

\begin{abstract}
Ground granulated blast furnace slag (GGBFS) is a by-product obtained from the iron making process and has suitable properties to be utilized as high volume cement replacement to produce sustainable concrete. This study focuses on investigating the influence of GGBFS replacement level $(0 \%-70 \%)$ and water/binder ratio $(0.45$ and 0.65$)$ on the performance of cement mortar blends. In order to characterize the engineering performance, the compressive strength of the mortar blends was evaluated. Whereas to ascertain the carbon footprint, environmental life cycle assessment was conducted. Besides the compressive strength and carbon footprint, the materials cost for each mortar blends was computed. Based on the compressive strength/carbon footprint ratio analysis, it was found that increased replacement level of GGBFS gave better performance while the cost efficiency analysis shows that suggested GGBFS replacement level of up to $50 \%$. Overall, in considering the strength performance, carbon footprint and materials cost, the recommended GGBFS replacement level for cement blends is $50 \%$. In addition, when the binder content is kept constant, mortar blends with lower water/binder ratio is preferable when considering the same parameters.
\end{abstract}

Keywords: ground granulated blast furnace slag; sustainability; life cycle assessment; cement replacement; Malaysia

\section{Introduction}

Among the constituent materials in concrete, cement is the largest contributor to the release and emission of carbon dioxide $\left(\mathrm{CO}_{2}\right)$. As much as $4 \%-6 \%$ of the global $\mathrm{CO}_{2}$ emissions is due to the production of cement. This is due to direct emission from calcination of calcium carbonate as well as indirect emission from combustion of fossil fuel used for calcination, mineral production and transportation [1]. Considering that concrete is one of the most widely used materials worldwide, the $\mathrm{CO}_{2}$ emission associated with the use of cement is a major environmental concern. Due to this, there have been numerous strategies adopted to reduce such impact, and one of the most commonly used method is through partially substituting cement with supplementary cementitious material (SCM) to produce blended cement [2]. SCM commonly consists of materials with pozzolanic reactivity such as fly ash or self-hydraulic properties such as ground granulated blast furnace slag (GGBFS). It is known that the use of such materials can improve the later age strength and durability properties of concrete when incorporated at the respective optimum amount [3].

GGBFS is manufactured from blast furnace slag, which is a product from the iron-making process. The blast furnace used in making iron operates at temperatures up to $2000{ }^{\circ} \mathrm{C}$ which is fed with 
mixtures of iron ore, coke and limestone. The iron ore is then converted into iron and sinks to the bottom of the blast furnace while the remaining materials form a slag that floats on top of the iron. The blast furnace slag is then rapidly quenched with water, and this granulation process is followed by drying and grinding to finer powdered form. The resultant GGBFS has amorphous/glassy phase and exhibits cementitious properties [4]. The primary composition of GGBFS is silicon dioxide $\left(\mathrm{SiO}_{2}\right)$, calcium oxide $(\mathrm{CaO})$ and magnesium oxide $(\mathrm{MgO})$. It has been reported that the use of GGBFS brings upon many advantageous properties to concrete, such as reduced heat of hydration, enhanced long term compressive strength, increased durability of concrete $[5,6]$. Another benefit of using GGBFS is the potential for use at high volume cement replacement due to its self cementitious properties. However, the use of high volume GGBFS as cement replacement could be accompanied by reduction in properties of concrete, such as the mechanical strengths. As the hydraulic activity of GGBFS is slower than that of cement, excessive use of GGBFS would retard the hydration process and hence slowing down the strength development of concrete. Despite this, various studies have explored the use of high volume GGBFS in different types of concrete [7-9], demonstrating satisfactory performance. The possibility of using GGBFS at high volume makes it an attractive option as SCM in consideration of the environmental point of view. The higher amount of GGBFS replacing cement in concrete, the lesser carbon footprint is expected due to lower cement content used.

Nevertheless, to produce a more sustainable concrete with cement-GGBFS blends, it is important to take into account the strength requirement and associated $\mathrm{CO}_{2}$ emission when formulating the mixture. Blends with a high amount of GGBFS may give lower environmental impact but insufficient compressive strength and vice versa. In order to take into account both aspects, optimization between both of the parameters should be available. In earlier studies, little optimization has been done on the compressive strength-carbon footprint of concrete mixtures and was mainly based on strength efficiency which takes into account only the compressive strength and total cement content $[10,11]$. Later on, indices were proposed to take in account the ratio of the compressive strength to $\mathrm{CO}_{2}$ emission ratio, with the latter values obtained from life cycle assessment (LCA) [12,13]. LCA is a powerful tool that can be used to help quantify the environmental impact of a concrete mixture based on the production phase of each constituent material, which includes extraction, transportation and processing, among others through a "cradle-to-gate" approach [14].

While research has been done to optimize the performance to carbon footprint of concrete, the influence of its mix proportion is not often looked at. For instance, the influence and reactivity of GGBFS in cement-based materials was said to be different with different mix proportions [15]. Besides that, there were few researches which revealed a more beneficial effect of low water/cement ratio on GGBFS-blended cement concrete [16,17]. As such, it would be interesting to assess the influence of mix compositions on the strength/carbon footprint optimization in GGBFS-blended cement concrete, in an effort to further promote the use of GGBFS in sustainable concretes. For this reason, the study will deal with evaluating the influence of GGBFS replacement level $(0 \%-70 \%)$ and the water/binder ratio $(0.45$ and 0.65 ) on the compressive strength of GGBFS-cement blends. LCA using local database will also be conducted considering these mix proportions to determine the respective embodied carbon footprint in the local context. This would allow the optimization of compressive strength/carbon footprint of the GGBFS-cement blends. Furthermore, cost analysis based on the local market price of materials to ascertain the cost efficiency of the GGBFS-cement blends and hence to optimize more practical blends which take into account strength, carbon footprint and cost considerations.

\section{Experimental Program}

\subsection{Materials}

The binder used for producing the mortar blends consisted of Type I ordinary Portland cement (OPC) and GGBFS. The OPC and GGBFS was sourced locally in Malaysia. The major oxide compositions of the GGBFS is given in Table 1 and the GGBFS had specific surface area of $430 \mathrm{~m}^{2} / \mathrm{kg}$. Local mining 
sand was used as the fine aggregate to produce the mortar blends while tap water in the laboratory was used as the mixing water.

Table 1. Major oxide compositions of materials.

\begin{tabular}{ccccccccc}
\hline Oxide & $\mathbf{C a O}$ & $\mathbf{A l}_{2} \mathbf{O}_{3}$ & $\mathbf{S i O}_{2}$ & $\mathbf{K}_{\mathbf{2}} \mathbf{O}$ & $\mathbf{N a}_{\mathbf{2}} \mathbf{O}$ & $\mathbf{M g O}$ & $\mathrm{TiO}_{2}$ & LOI \\
\hline$\%$ & 43.3 & 11.9 & 34.6 & 0.39 & 0.19 & 5.2 & 0.46 & 1.6 \\
\hline
\end{tabular}

The variables adopted in this study were water/binder ratio (0.45 and 0.65) and the GGBFS replacement level (from $0 \%$ to $70 \%$ at $10 \%$ incremental level). The mix proportions for the mortar blends are given in Table 2. The A-series mix represents blends at 0.45 water/binder ratio while B-series are blends with 0.65 water/binder ratio. The number in the mix designation denotes the amount of GGBFS replacement level; for example, A1 represents the blends with 10\% GGBFS replacement level with a water/binder ratio 0.45 , B2 represents blends with 20\% GGBFS replacement level with a water/binder ratio of 0.65 . The mixes were designed in a way that the total cement content remained constant and in order to fix the water/binder ratio, the sand content was adjusted based on total volume of materials.

Table 2. Mix proportion for mortar blends.

\begin{tabular}{ccccc}
\hline \multirow{2}{*}{ Blend } & \multicolumn{3}{c}{ Content $\mathbf{( k g / \mathbf { m } ^ { 3 } )}$} \\
\cline { 2 - 4 } & Cement & GGBFS & Sand & Water \\
\hline A0 & 540 & 0 & 1560 & 243 \\
A1 & 486 & 54 & 1560 & 243 \\
A2 & 432 & 108 & 1560 & 243 \\
A3 & 378 & 162 & 1560 & 243 \\
A4 & 216 & 1560 & 243 \\
A5 & 324 & 270 & 1560 & 243 \\
A6 & 270 & 324 & 1560 & 243 \\
A7 & 216 & 378 & 1560 & 351 \\
B0 & 162 & 0 & 1270 & 351 \\
B1 & 540 & 54 & 1270 & 351 \\
B2 & 486 & 108 & 1270 & 351 \\
B3 & 432 & 162 & 1270 & 351 \\
B4 & 378 & 216 & 1270 & 351 \\
B5 & 324 & 270 & 1270 & 351 \\
B6 & 270 & 324 & 1270 & 351 \\
B7 & 216 & 378 & 1270 & \\
\hline
\end{tabular}

\subsection{Procedure}

The mixing process was carried out in accordance with ASTM C305. Water was initially added to the mixing bowl followed by the binder materials (cement or/and GGBFS) and mixed at low speed. The sand was added slowly while mixing was on-going and mixed for $30 \mathrm{~s}$. Finally, the mixing speed was increased for a period of $60 \mathrm{~s}$ upon allowing the mixture to stand for $90 \mathrm{~s}$. To produce $50 \mathrm{~mm}$ cube-sized mortar specimens, the fresh mortar mixture was placed in the prepared steel moulds and compacted in 2 layers via a vibration table. Upon completion of the casting process, the moulds were kept in the laboratory for 1 day. The moulds were de-moulded the next day and cured in the laboratory (relative humidity: 70\%-85\%) until the age of testing. Compressive strength test was carried out on the $50 \mathrm{~mm}$ cube specimens at the age of 28 days in accordance with ASTM C109. The compressive strength was determined based on the average obtained from testing of 5 specimens for each mixture.

\section{Environmental Life Cycle Assessment (eLCA)}

This environmental assessment follows the standard protocol of life cycle assessments, LCA, (ISO 14040-14043). LCA is a tool used to determine the environmental performances of products, processes or services, through their production, distribution, usage, maintenance, and disposal stage. It is a systematic set of procedures developed to compile, examine, and evaluate the material and energy balance of the system by converting those inputs and outputs to associate with potential environmental 
impact that is directly attributable to the operation of a product or service system throughout its entire life cycle. LCA is one of the most effective and common methods used for evaluation and comparison of the environmental impact of different concrete mix design [18-20]. Hence, LCA can help in decision making of selecting suitable mix designs based on environmental performances. There are four main stages in a life cycle assessment. First is the goal and scope definition that identifies the LCA's purpose, the system boundaries and assumptions used in the study. The second stage is the life cycle inventory (LCI) step that quantifies type of raw materials which will be used and the type of emissions that will take place in the study boundaries. The third stage is the life cycle impact assessment (LCIA) that clarifies the intensity of the LCI results with respect to their environmental impact. LCIA alone is divided into four main procedures which are (i) classification and characterization, (ii) normalization, (iii) weighting, and (iv) sensitivity analysis. In the classification stage, all inventory data are sorted into impact categories according to their environmental impact. While in the characterization stage, the inventory data will be multiplied by a characterization factor to differentiate the substances according to their severity within each impact category. In normalization stage, the magnitude of each impact categories is calculated relative to the total impacts in the region of interest. In the weighting stage, all normalized impact categories are multiplied by each weighting factors to represent the relative importance of each impact. The fourth and final stage of LCA is where interpretation is conducted to identify, quantify, check, and evaluate information from the results of the LCA [21].

In this study, LCA with cradle-to-gate analysis is selected to evaluate the environmental impacts associated with the production of mortar mix from raw material extraction through materials processing and manufacture. The functional unit for this LCA study was defined as $1 \mathrm{~m}^{3}$ of mortar. The life cycle assessment was carried out using the SimaPro software version 9, due to its reputation as an accredited LCA tool that is widely used globally. The software comes with the Ecoinvent database (version 3.5) libraries as well as various impact assessment methods. Among available LCIA methods, the ReCiPe 2016 version 1.03 was chosen to quantify the embodied carbon footprint of different GGBFS-cement blends proportion. ReCiPe has the broadest midpoint impact categories and impact mechanisms that addresses global scope. ReCiPe impact assessment methodology converts the long list of life cycle inventory (LCI) results (raw materials, energies, emissions etc) into a limited number of indicator scores which represent relative severity on 18 environmental impact categories (midpoint level) and three environmental impact categories (endpoint level) (Figure 1). A detailed description of the methodology is provided by Huijbregts et al. [22].

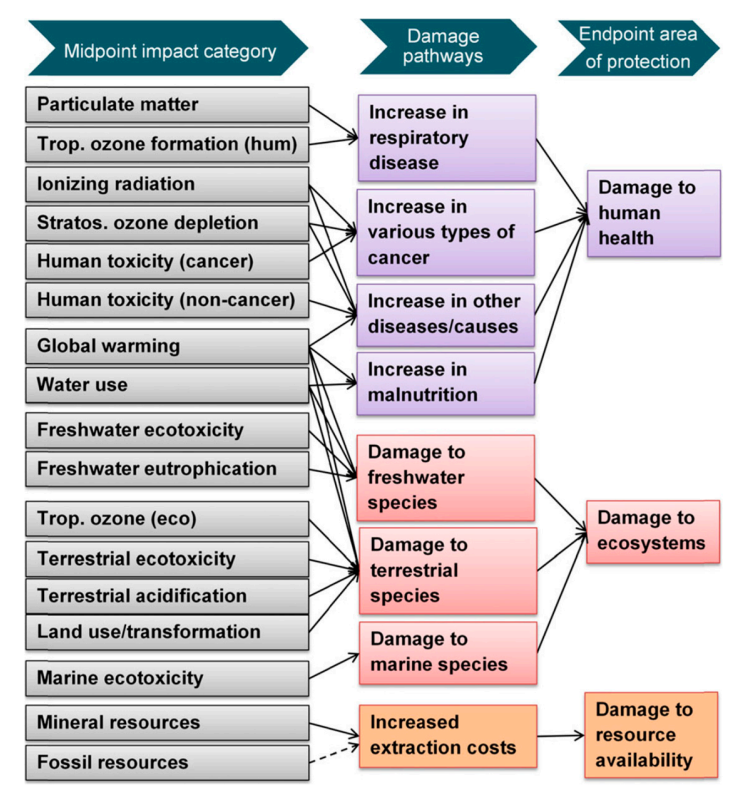

Figure 1. Overview of the impact categories that are covered in the ReCiPe2016 method and their relation to the areas of protection [22]. 


\subsection{System Boundary}

The system boundary (Figure 2) includes all the inputs for producing mortar, such as extraction and processing of raw materials up to the production of cement, sand, water, and electricity. The system boundary does not include transportation. GGBFS is a by-product from iron and steelmaking, therefore, any emissions or resources allocated to the production of steel are not seen as relevant in terms of the concrete production and have not been included inside the system boundary, only the emissions and resource from the processing of GGBFS for the purpose of mixing is included in this assessment.

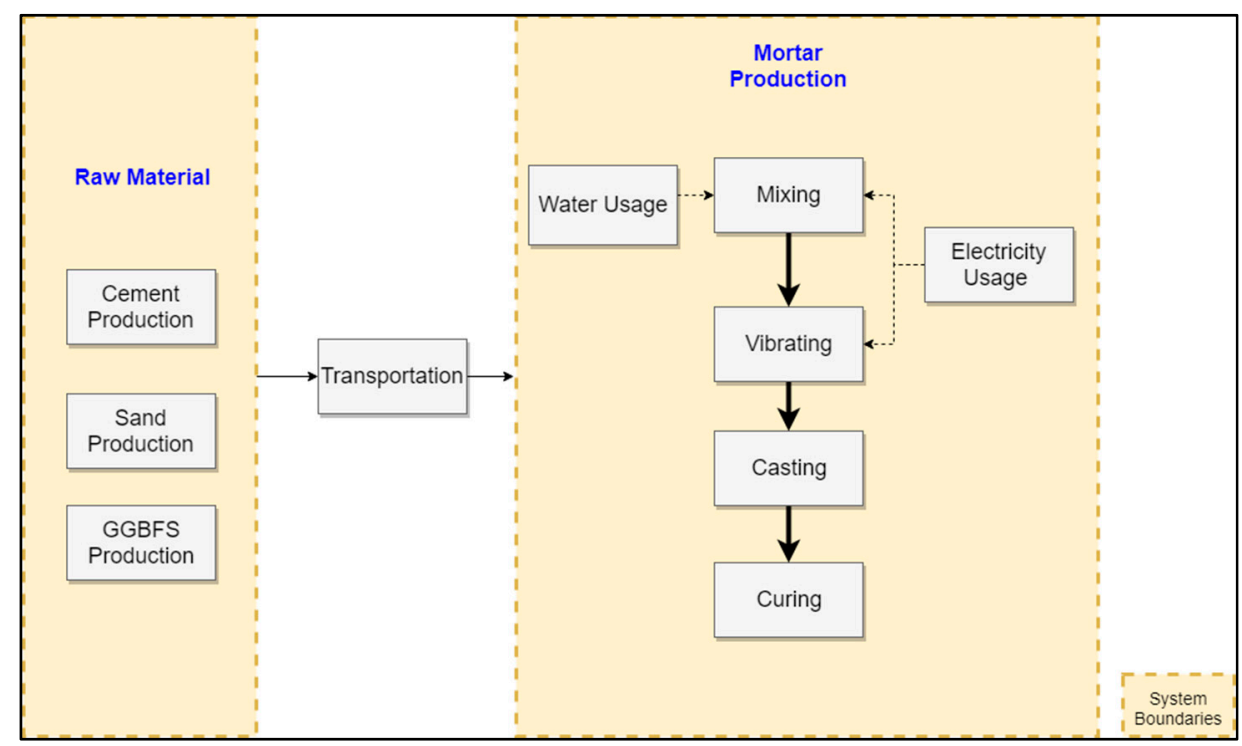

Figure 2. System boundary of life cycle assessment (LCA) on mortar production.

\subsection{Life Cycle Inventory}

In this stage, compilation and quantification of all the inputs as well as the outputs throughout the entire life cycle of each mortar blend are carried out. The data will be inserted into the SimaPro LCA software for each mix design which included all the processes and materials that been highlighted in the system boundary (Figure 2). The life cycle inventory (LCI) data were taken from two sources, Ecoinvent database version 3.5 (default in the SimaPro software) and local MYLCID (Malaysia Life Cycle Inventory database) dataset acquired from SIRIM (Malaysia) Berhad. The inventory selection was made based on the LCI database (Ecoinvent 3.5 and MY-LCID) which exactly or partially matches the processes and materials used in the experiment with priority to choose the database from MY-LCID. Since there are currently only three inventories (cement, sand, and electricity) are available for selection from the local MY-LCID database, the rest of the inventories (water, and GGBS) have to be acquired from Ecoinvent database. The MY-LCID database were inserted into SimaPro software as system level process. The database and inventory selected for this study are as shown in Table 3. The example of inventory data for mortar blend A1 inserted into SimaPro software is as shown in Figure 3.

Table 3. Life Cycle Inventory and database.

\begin{tabular}{cccc}
\hline Inventory & Reference Database & $\begin{array}{c}\text { Geographical } \\
\text { Representativeness }\end{array}$ \\
\hline \multirow{3}{*}{ Raw Material } & Cement, CEM I 42.5 & MY-LCID & $\begin{array}{c}\text { Malaysia } \\
\text { Rest of the World } \\
\end{array}$ \\
& GGS & Ecoinvent & Rest of the World \\
& Sand, 0/2 & Ecoinvent & Malaysia \\
\hline Energy & Electricity, PM & MY-LCID & Malaysia \\
\hline
\end{tabular}




\begin{tabular}{|c|c|c|c|}
\hline A1 & \multirow[b]{2}{*}{ Amount } & \multirow[b]{2}{*}{ Unit } & \multirow[b]{7}{*}{ Unit } \\
\hline Materials/Assemblies & & & \\
\hline Cement, Portland $\{\mathrm{MY}\} \mid$ production mix, at plant; CEM 42.5 |S & 486 & $\mathrm{~kg}$ & \\
\hline Ground granulated blast furnace slag $\{$ RoW $\} \mid$ production $\mid$ APOS, S & 54 & $\mathrm{~kg}$ & \\
\hline Tap water $\{$ RoW\} $\mid$ market for $\mid$ APOS, S & 243 & $\mathrm{~kg}$ & \\
\hline Sand $\{\mathrm{MY}\} \mid$ production mix, at plant, grain size $0 / 2 \mid \mathrm{S}$ & 1560 & $\mathrm{~kg}$ & \\
\hline Processes & \multicolumn{2}{|c|}{ Amount } & \\
\hline Electricity, grid mix $\{$ Peninsular MY\}| AC, consumption mix, to consu & & $938 / 0.000625$ & $\mathrm{kWh}$ \\
\hline
\end{tabular}

Figure 3. Inventory for mortar blend A1 inserted into SimaPro software.

\section{Results and Discussion}

\subsection{Compressive Strength}

Figure 4 shows the 28 day compressive strength of the GGBFS blends with a water/binder ratio of 0.45 and 0.65 . As expected, the compressive strength of the blends with a water/binder ratio of 0.45 was higher than the corresponding blends with a water/binder ratio of 0.65 . The difference in strength between these two sets of blends was found to be in the range of $20 \%-30 \%$. Lower water/binder ratio typically gives higher compressive strength to the mix due to the lower number of voids formed. In general, it can be observed that despite the very high replacement level of cement with GGBFS by up to 70\%, sufficient and adequate compressive strength could be achieved. For the 70\% GGBFS blends with a water/binder ratio of 0.45 and 0.65 , the 28 day compressive strength was $35.6 \mathrm{MPa}$ and $26.1 \mathrm{MPa}$, respectively.
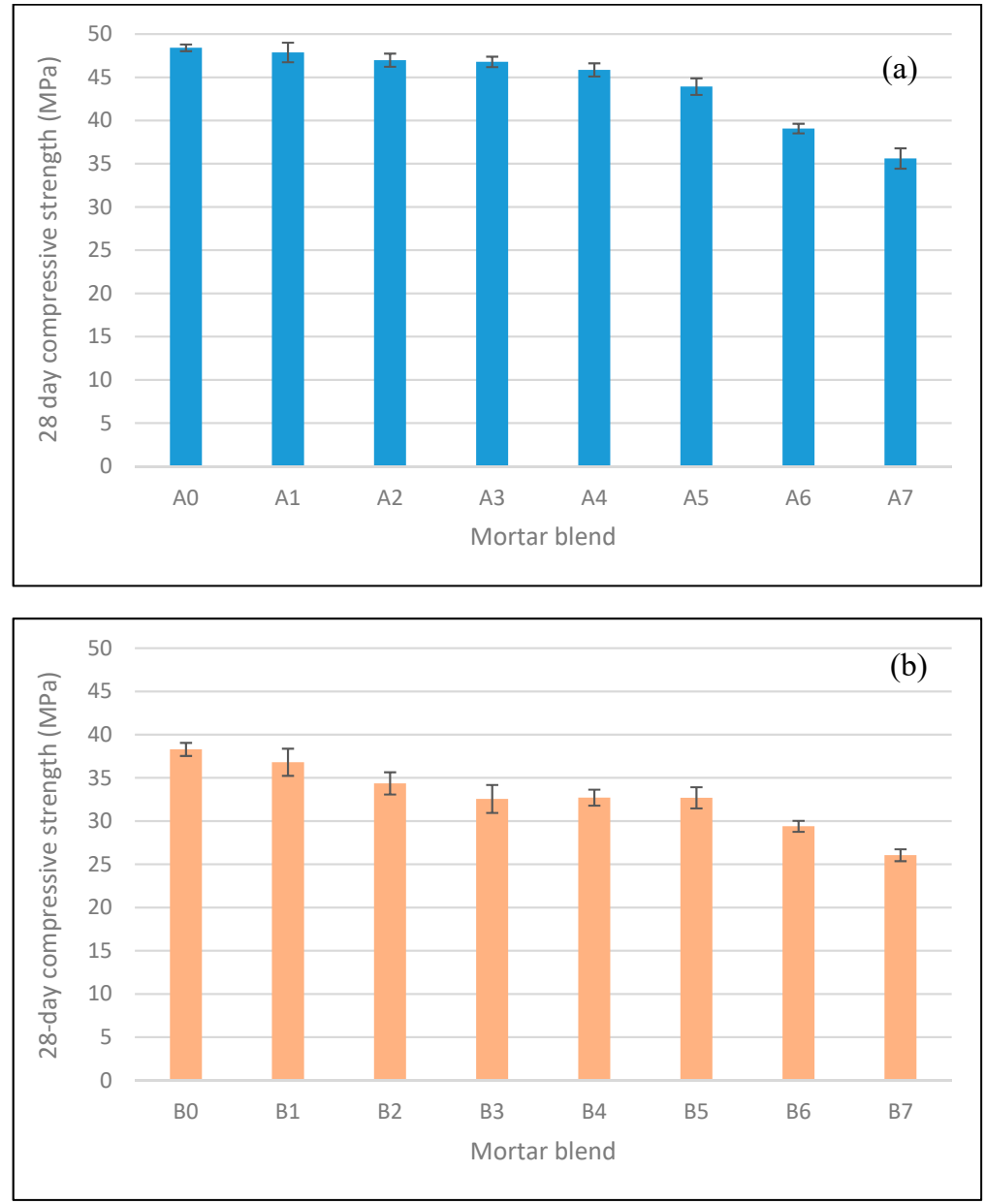

Figure 4. Compressive strength of ground granulated blast furnace slag (GGBFS) blends at water/binder ratio of (a) 0.45 and (b) 0.65 . 
It can be clearly seen that as the GGBFS replacement level increased, the compressive strength of the blends was reduced. The reduction in the compressive strength was determined to be up to around $26 \%$ and $31 \%$ for the $70 \%$ GGBFS blends with a water/binder ratio of 0.45 and 0.65 , respectively. The main contributing factor in the strength decrease was the dilution effect when cement was substituted by GGBFS. Even though GGBFS typically exhibits self-cementitious properties, it hydrates at a slower rate compared to OPC. Therefore, GGBFS blends had lower amount of hydration products and this resulted in lower compressive strength compared to the blend without GGBFS at the age of 28 days. However, it can be noted that the difference in strength between the blend without GGBFS and blends with up to $40 \%$ was as low as only $5 \%$, particularly for blends with a water/binder ratio of 0.45 . The slight difference could possibly be overcome at later ages considering GGBFS blends typically have better later strength due to the continuous hydration and some pozzolanic reaction [15]. A slight reduction in the 28 day compressive strength of concrete containing GGBFS at 30\% replacement level or higher was also observed by Zhou et al. [23]. Additionally, Gholampour and Ozbakkaloglu [24] similarly reported that use of $50 \%$ GGBS resulted in only about a $9 \%$ reduction in the 7 day compressive strength of concrete, and a strength improvement up to $6 \%$ was found after 28 days. It is also interesting to note that as the GGBFS replacement level was increased, the rate of strength reduction observed was less for the blends with a water/binder ratio of 0.45 , in particular for a substitution level of GGBFS of up to $40 \%$ (reduction of up to $5 \%$ ). Comparatively, for the blends with a water/binder ratio of 0.65 , the reduction in compressive strength was more gradual (reduction of up to $15 \%$ with $40 \%$ GGBFS) with noticeable reduction at each GGBFS substitution level. This observation agrees well with past findings whereby a lower water/binder ratio is more favourable in concrete mixes containing GGBFS [17]. A possible explanation of this is due to the optimum amount of water present in the system which could participate in the hydration process and react with OPC and the GGBFS effectively.

\subsection{Life Cycle Impact Assessment}

The life cycle impact assessment (LCIA) was carried out using the SimaPro software, with the ReCiPe 2016 methodology for 18 midpoint (problem-oriented) and three endpoint (damage-oriented) impact categories, with hierarchist cultural perspective (default preference). The LCIA translates material flows, energy flows, and emissions into a limited number of indicator scores that represent relative severity on environmental impact categories distinguished by different stages in the cause-effect chain of environmental impact, referring to midpoint and endpoint modelling [22].

The primary aim of this stage is to identify the significance and magnitude of the environmental impacts and subsequently identify the main process responsible for the potential impacts associated with the production of the control mortar blend (A0/B0).

Table 4 shows the 18 midpoint environmental impacts for the production of $1 \mathrm{~m}^{3}$ mortar blend A0 with a water/binder ratio of 0.45 and mortar blend B0 with a water/binder ratio 0.65 . The highest score of impact categories in terms of absolute values is observed for global warming potential, terrestrial ecotoxicity, human non-carcinogenic toxicity, land use impact, and fossil resource scarcity. The results also shown that different water/binder ratios $(0.45$ or 0.65$)$ to produce mortar blend have minimum influence on the environmental impacts with variation not more than $15 \%$.

Figures 5 and 6 summarize the contribution of each inventory (raw materials and energy usage) to 18 impact categories for mortar blend A0 and B0. In both figures, it can be seen that the usage of cement (dark green) in mortar production contributed the majority of the environmental impacts for all of the impact categories, except for the freshwater eutrophication impact from mortar blend B0 contributed by water usage (light green).

The endpoint method is next applied to translate midpoint environmental impacts into damage-oriented impact categories of human health, ecosystem quality, and resource scarcity. The endpoint indicator is useful to the policymakers to interpret the midpoint indicator results and their relevance to the areas of protection (human health, ecosystem quality, and resources impacts) [25]. 
Table 5, Figures 7 and 8 summarize the endpoint results of the contribution of each inventory to the production of mortar blend $\mathrm{A} 0$ and $\mathrm{B} 0$. From the figures, it indicates that the usage of cement contributes to almost $85 \%-95 \%$ of the impacts for mortar production, while other process such as electricity, water, and sand usage, contribute only $5 \%-15 \%$ of the impacts. The endpoint analysis shows similar results and trends to those observed in midpoint analysis.

In order to gain a better understanding of the relative size of each damage categories, a normalization stage is required. LCA normalisation offers a reference situation of the relative size of each damage categories on the environment. Since all these damage categories have different units, LCA normalisation makes it possible by translating the different impact scores into dimensionless number before applying of dimensionless weighting factors upon these damage categories [14]. In the normalization result (Table 5, Figures 9 and 10), damage to human health contributed $90 \%$ of the total environmental impacts, while damage to ecosystem contributed $9 \%$, and damage to resources contributed less than $1 \%$. Most of the contribution to the damage to human health come from the emissions of carbon dioxide from the production of cement. Thus, it is obvious that to reduce the overall environmental impact from the production of cement-based materials or concrete, it is necessary to partially replace cement.

Table 4. The midpoint impact assessment results for the production of mortar blend A0 and B0 in $1 \mathrm{~m}^{3}$.

\begin{tabular}{cccc}
\hline Impact Category & Unit & A0 & B0 \\
\hline Global warming potential & $\mathrm{kg} \mathrm{CO}$ eq & 574.033 & 573.209 \\
Stratospheric ozone depletion & $\mathrm{kg} \mathrm{CFC11} \mathrm{eq}$ & $2.65 \times 10^{-5}$ & $2.65 \times 10^{-5}$ \\
Ionizing radiation & $\mathrm{kBq} \mathrm{Co-60} \mathrm{eq}$ & 0.050 & 0.055 \\
Ozone formation, Human health & $\mathrm{kg} \mathrm{NO}$ eq & 1.255 & 1.255 \\
Fine particulate matter formation & $\mathrm{kg} \mathrm{PM2.5} \mathrm{eq}$ & 0.535 & 0.534 \\
Ozone formation, Terrestrial ecosystems & $\mathrm{kg} \mathrm{NOx} \mathrm{eq}$ & 1.258 & 1.258 \\
Terrestrial acidification & $\mathrm{kg} \mathrm{SO}$ eq & 1.770 & 1.767 \\
Freshwater eutrophication & $\mathrm{kg} \mathrm{P} \mathrm{eq}$ & $2.10 \times 10^{-4}$ & $2.41 \times 10^{-4}$ \\
Marine eutrophication & $\mathrm{kg} \mathrm{N} \mathrm{eq}$ & $7.04 \times 10^{-4}$ & $6.97 \times 10^{-4}$ \\
Terrestrial ecotoxicity & $\mathrm{kg} \mathrm{1,4-DCB}$ & 147.647 & 147.289 \\
Freshwater ecotoxicity & $\mathrm{kg} \mathrm{1,4-DCB}$ & 0.017 & 0.019 \\
Marine ecotoxicity & $\mathrm{kg} \mathrm{1,4-DCB}$ & 0.087 & 0.090 \\
Human carcinogenic toxicity & $\mathrm{kg} \mathrm{1,4-DCB}$ & 0.135 & 0.149 \\
Human non-carcinogenic toxicity & $\mathrm{kg} \mathrm{1,4-DCB}$ & 10.932 & 10.938 \\
Land use & $\mathrm{m}{ }^{2} \mathrm{a} \mathrm{crop} \mathrm{eq}$ & 21.138 & 20.939 \\
Mineral resource scarcity & $\mathrm{kg} \mathrm{Cu} \mathrm{eq}$ & 1.181 & 1.175 \\
Fossil resource scarcity & $\mathrm{kg} \mathrm{oil} \mathrm{eq}$ & 56.203 & 55.958 \\
Water consumption & $\mathrm{m}{ }^{3}$ & 1.391 & 1.494 \\
\hline
\end{tabular}

Table 5. The endpoint impact assessment results for the production of mortar blend A0 and B0 in $1 \mathrm{~m}^{3}$.

\begin{tabular}{cccccc}
\hline \multirow{2}{*}{ Impact Category } & \multicolumn{3}{c}{ Damage Assessment } & \multicolumn{2}{c}{ Normalization } \\
\cline { 2 - 6 } & Unit & A0 & B0 & A0 & B0 \\
\hline Human health & DALY & $1.23 \times 10^{-3}$ & $1.23 \times 10^{-3}$ & 0.052 & 0.052 \\
Ecosystems & species.yr & $4.02 \times 10^{-6}$ & $4.02 \times 10^{-6}$ & 0.006 & 0.006 \\
Resources & USD2013 & 6.918 & 6.835 & 0.000 & 0.000 \\
\hline
\end{tabular}




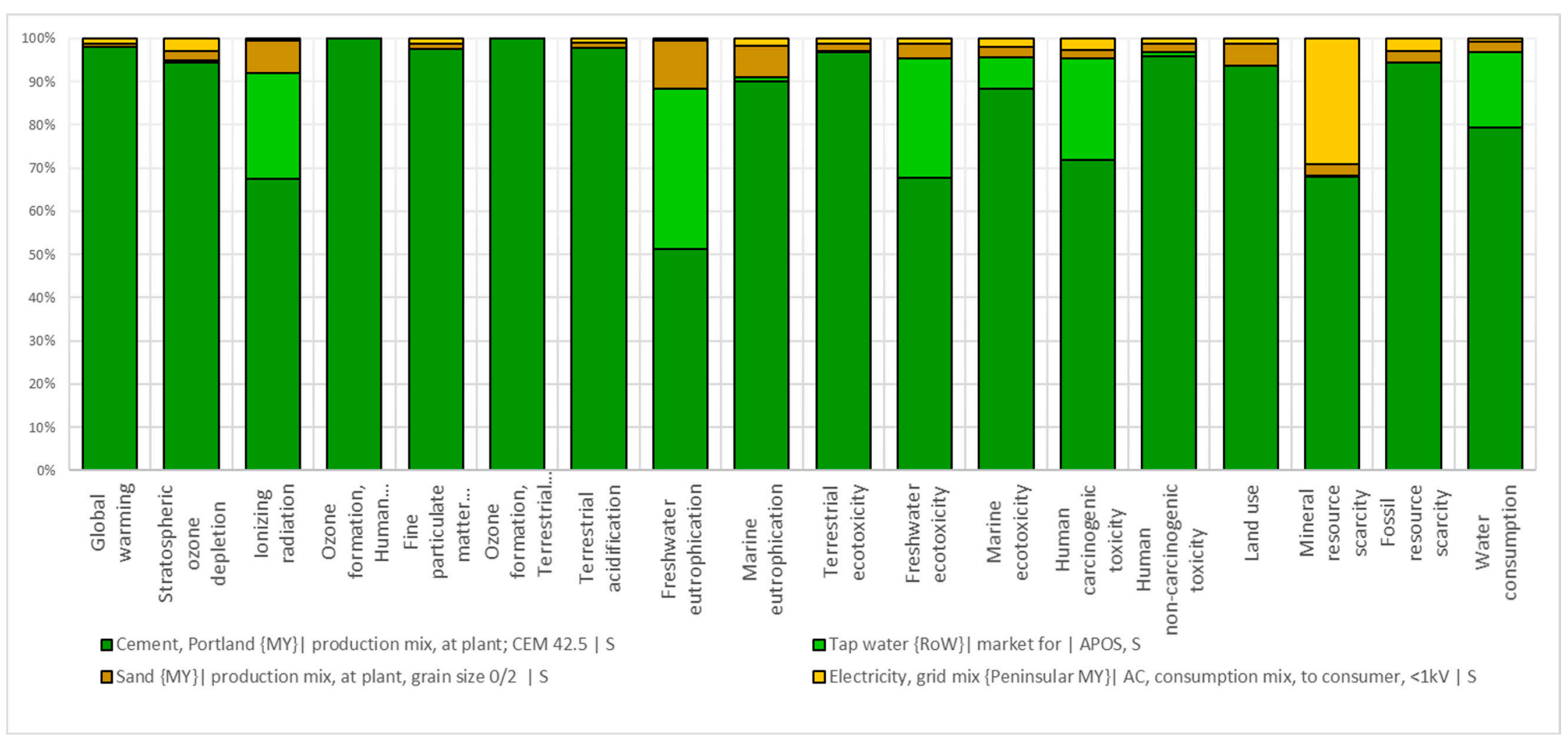

Figure 5. Aggregated contribution of processes to midpoint categories for production of mortar blend A0 (Results expressed in \% of total absolute value in Table 4). 


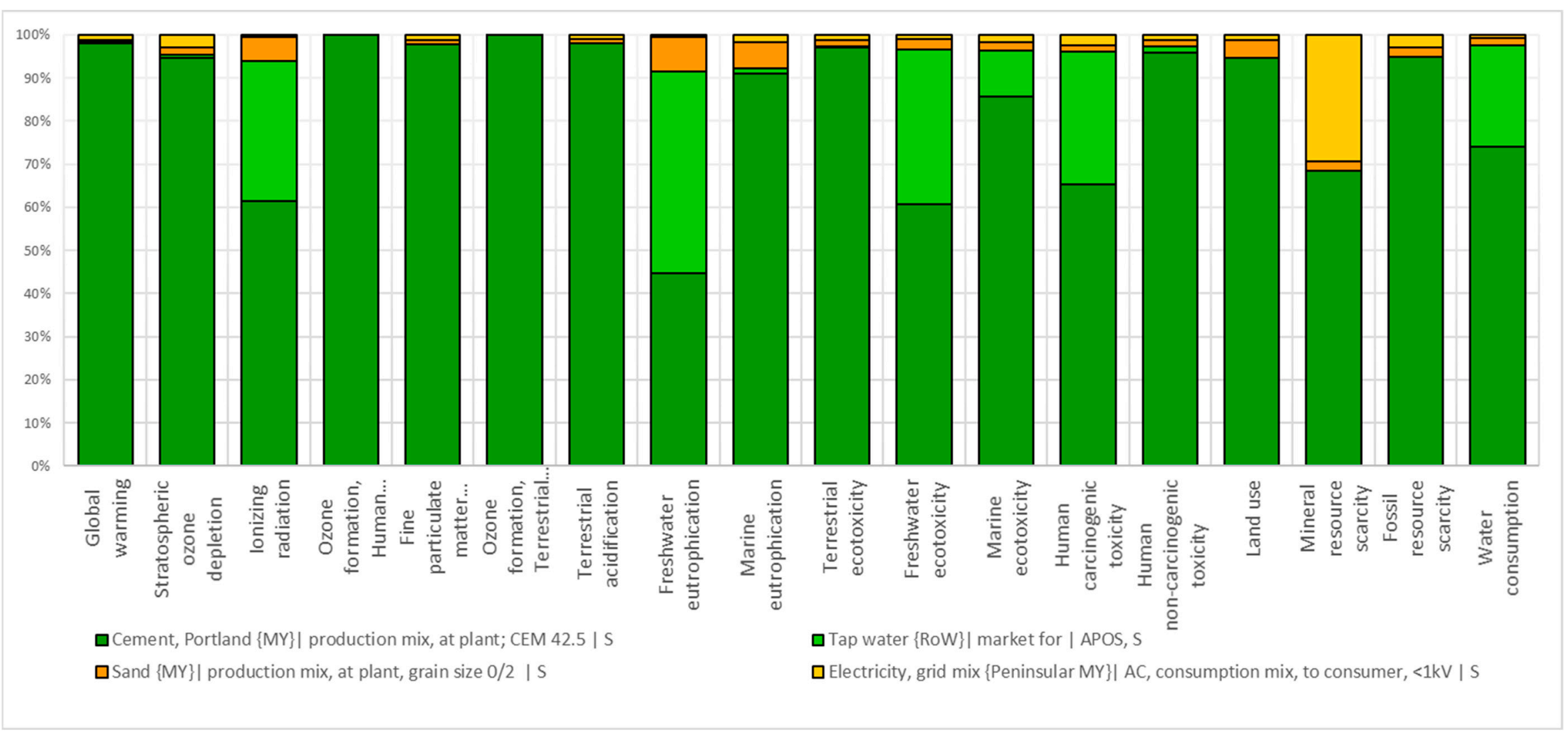

Figure 6. Aggregated contribution of processes to midpoint categories for production of mortar blend B0 (Results expressed in \% of total absolute value in Table 4). 


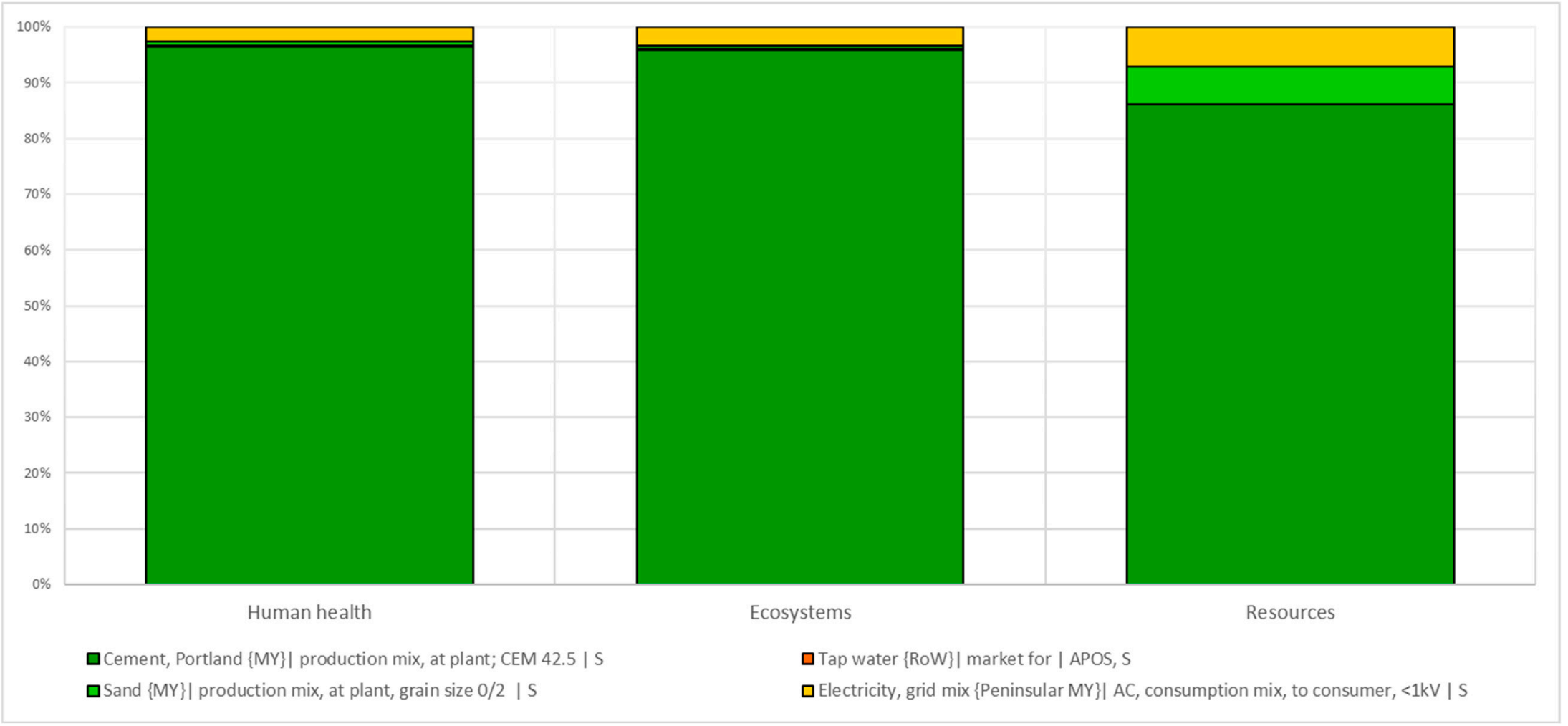

Figure 7. Aggregated contribution of processes to endpoint categories for production of mortar blend A0 (Results expressed in \% of total absolute value in Table 5). 


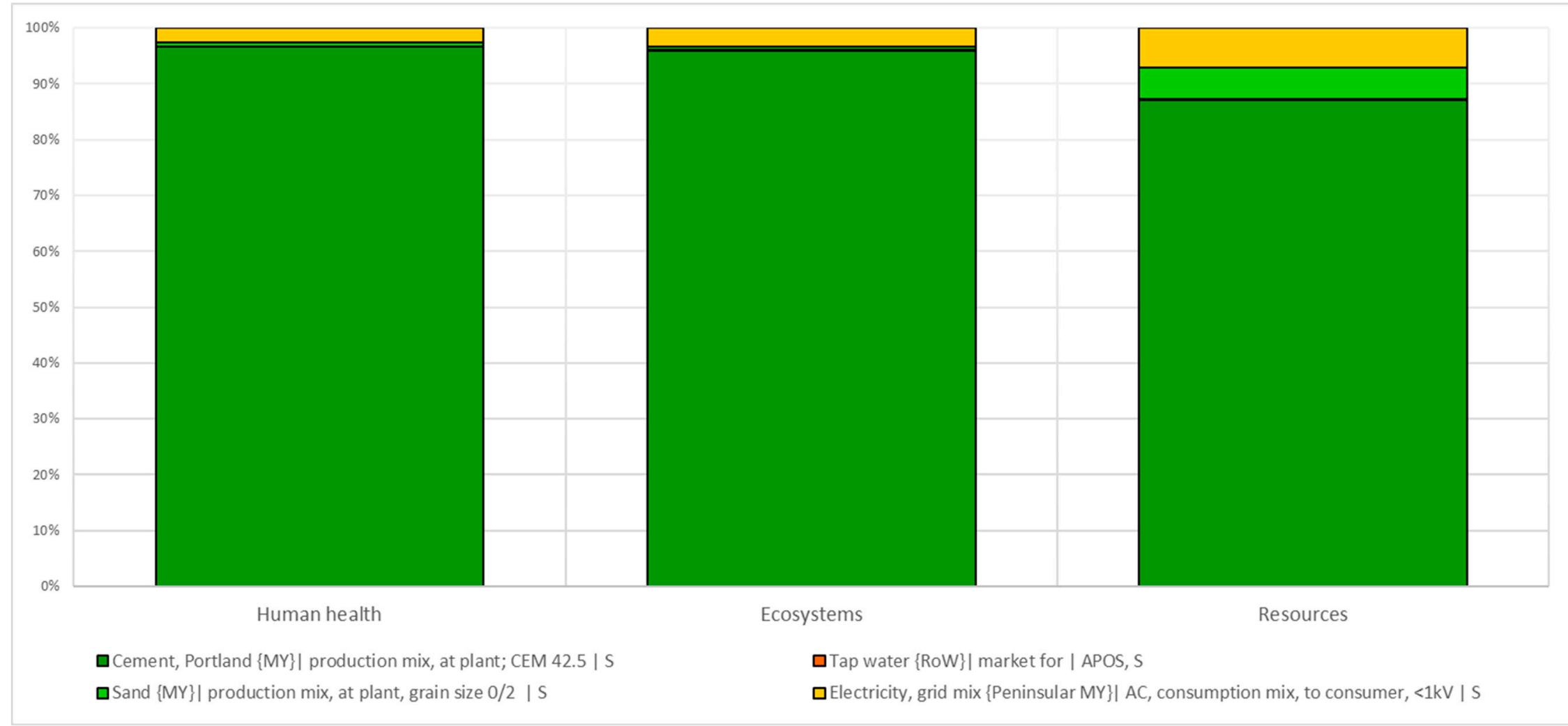

Figure 8. Aggregated contribution of processes to endpoint categories for production of mortar blend B0 (Results expressed in \% of total absolute value in Table 5). 


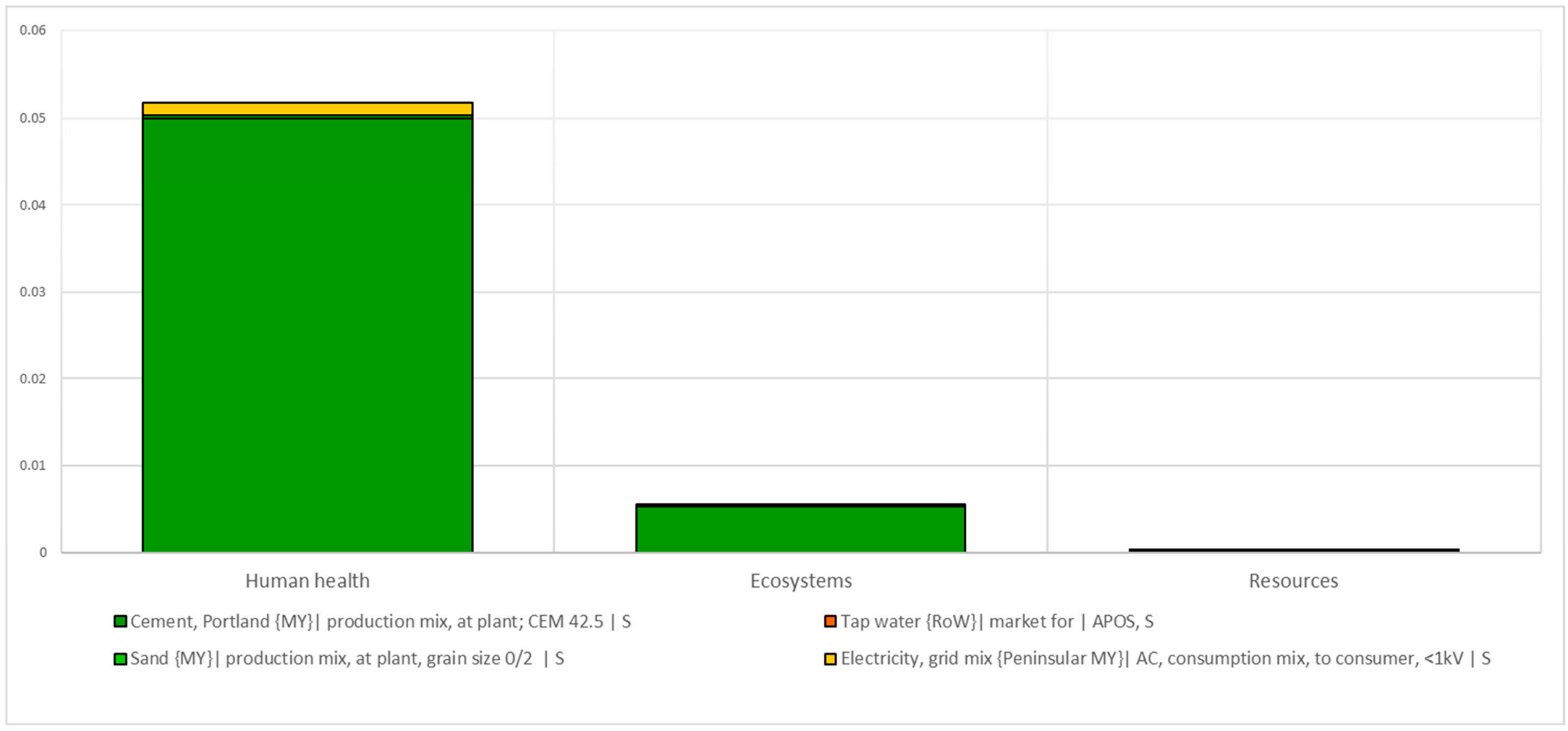

Figure 9. Normalization results of endpoint categories for production of mortar blend A0. 


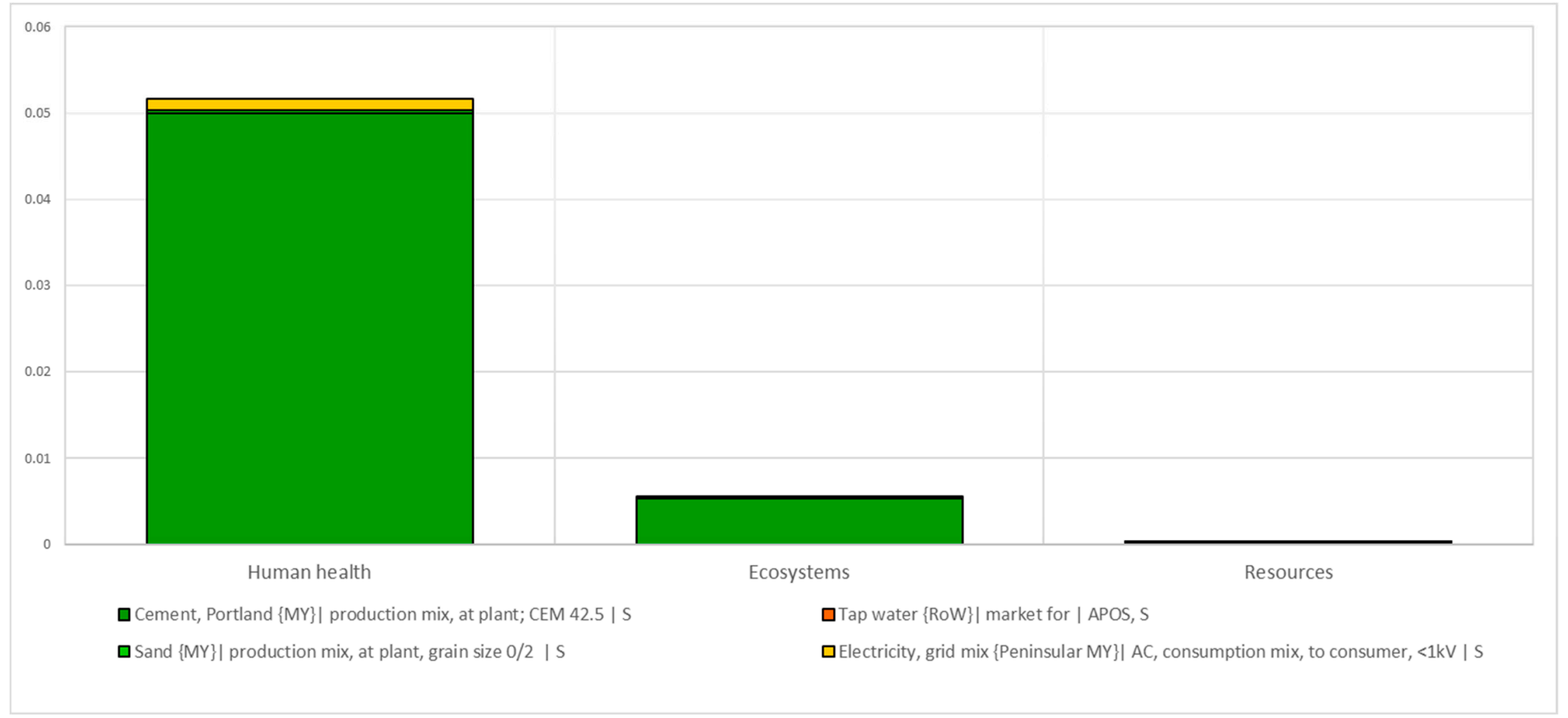

Figure 10. Normalization results of endpoint categories for production of mortar blend B0. 


\subsection{Sensitivity Analysis}

In order to assess the uncertainty of the impact results, the obvious way to do this is through sensitivity analysis. Sensitivity analyses should focus on the most significant variation used in assumptions, methods, or data that influence the outcome of the result. The sensitivity analysis that is often used in LCAs is scenario analysis, which refers to the different choices of the used model, input parameters and conditions outside of the studied system [26]. The sensitivity analysis in this study will examine how the environmental impacts are sensitive to changing of the databases (Ecoinvent default vs. MY-LCID). Since cement was found to be the key contributor to environmental impacts of mortar blend, the sensitivity analysis will apply in comparing different cement inventory dataset from Ecoinvent (Cement, Portland $\{$ RoW $\}$ |production|APOS, U) and MY-LCID (Cement, Portland \{MY\}|production mix, at plant; CEM I 42.5) in selected mortar blends (A1, A3, A5, and A7). The results (Figure 11) show that, in term of global warming potential and fossil resources scarcity, an average variation of $20 \%$ or less was reported. There is an average variation of $40 \%$ for the impact categories of stratospheric ozone depletion, ozone formations, fine particulate matter formation, terrestrial ecotoxicity, freshwater ecotoxicity, marine ecotoxicity and fossil, resource scarcity, while the rest of the impact categories have an average variation of more than $50 \%$. 


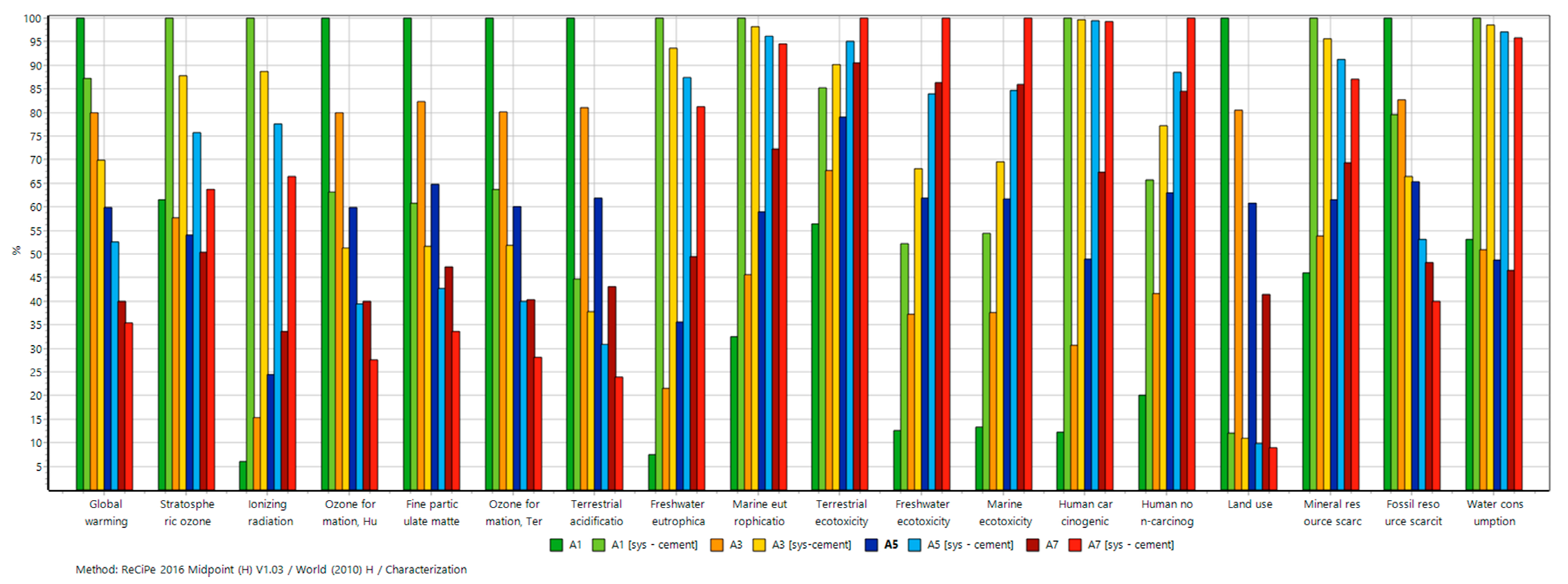

Figure 11. Impact assessment results of mortar blends A1, A3, A5, and A7 with Cement, Portland $\{M Y\}$ vs. Cement, Portland $\{$ RoW $\}$. 


\subsection{Carbon Footprint Performance}

The embodied carbon footprint of different mortar blends was evaluated through Global Warming Potential $\left(\mathrm{kg} \mathrm{CO}_{2} \mathrm{eq}\right)$ per volume $\left(\mathrm{m}^{3}\right)$ of each mixture. Figure 12 summarizes the GWP of mortar blends at water/binder ratio of 0.45 (A0-A7) and 0.65 (B0-B7). From the result, it can be determined that mix designs with both water/binder ratio of 0.45 and 0.65 have almost similar GWP. This indicates that the GWP of each mortar blend is independent of water/binder ratio of mix designs, when the binder content is kept constant.

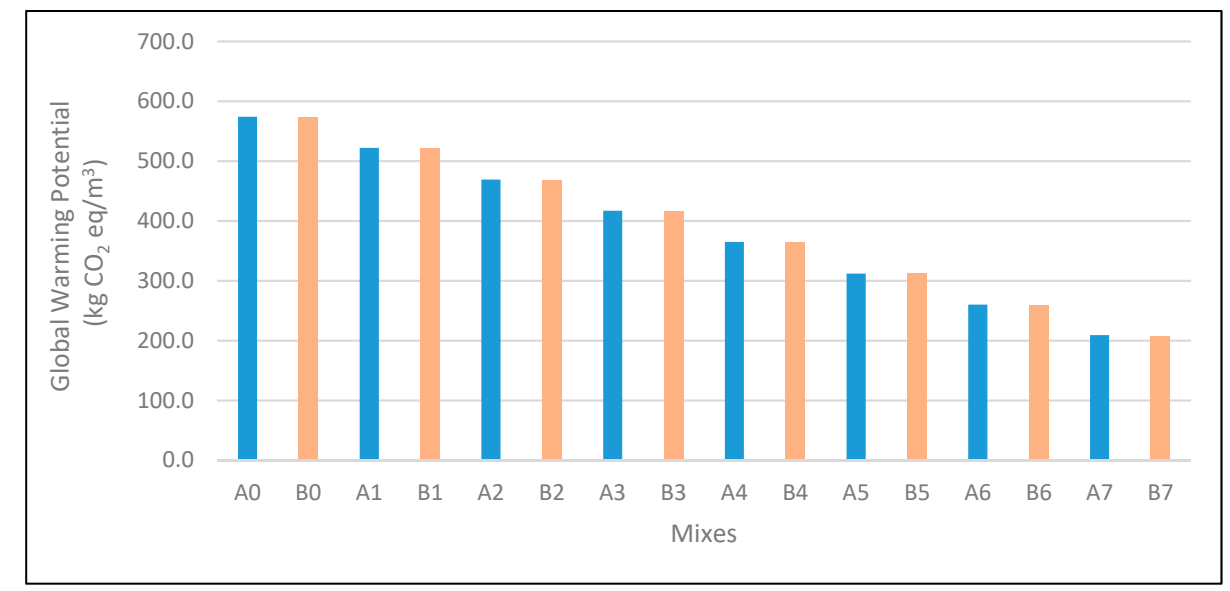

Figure 12. Global Warming Potential (GWP) $\left(\mathrm{kg} \mathrm{CO}_{2} \mathrm{eq} / \mathrm{m}^{3}\right)$ of mortar blends at water/binder ratio of 0.45 (A0-A7) and 0.65 (B0-B7).

The highest GWP was recorded for the mix with the highest cement content (A0/B0) with 574/573 $\mathrm{kg} \mathrm{CO} 2 \mathrm{eq} / \mathrm{m}^{3}$, while the lowest GWP was recorded for mortar blends with the lowest cement and highest GGBFS content (A7/B7) with 209/207 $\mathrm{kg} \mathrm{CO}_{2} \mathrm{eq} / \mathrm{m}^{3}$. This implies that the sole factor that affects the GWP in these mix designs is the replacement of cement with GGBFS. Figure 13 shows that the cement content is the major contributor to the GWP of the mortar blends, as the GWP value are directly proportional with the cement content in the mixes. With respect to optimum mix design, it is strongly recommended that GGBFS as SCM is selected as material for cement replacement with a potential in improving sustainability through reduction of carbon footprint.

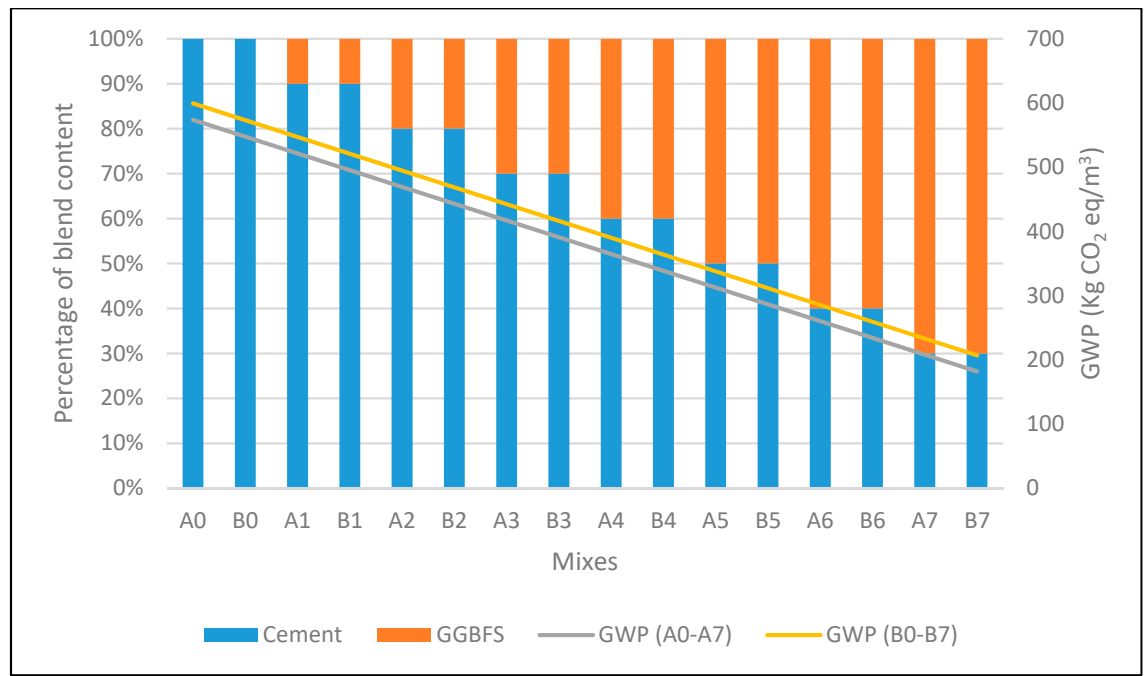

Figure 13. Blend content (\%) vs. Global Warming Potential $\left(\mathrm{kg} \mathrm{CO}_{2} \mathrm{eq} / \mathrm{m}^{3}\right)$. 


\subsection{Compressive Strength/Carbon Footrpint Analysis}

The compressive strength/carbon footprint ratio was computed to determine the most efficient blend, i.e., contribution of the blends towards the compressive strength with the least embodied $\mathrm{CO}_{2}$ and GWP. The higher the strength/carbon footprint ratio indicates a more efficient blend in terms of performance of concrete and the environmental impact. When the compressive strength/carbon footprint ratio is analysed in this study, it was found that blends from A-series (water/binder ratio $=0.45$ ) outperformed the corresponding blends from B-series (Figure 14). The ratio ranged between 0.084 and $0.170 \mathrm{MPa} / \mathrm{kg} \mathrm{CO}_{2}$ eq for the A-series blend while the ratio for B-series blend was between 0.067 and $0.126 \mathrm{MPa} / \mathrm{kg} \mathrm{CO}_{2}$ eq. The obtained ratios are generally within the range reported by Miller et al. [19] for normal concrete. The major reason for the superior efficiency of the A-series blends is due to its higher compressive strength associated with the lower water/binder ratio, while the GWP was similar for both series of blends. Nevertheless, it is interesting to note that in order to achieve better efficiency in blends with higher water/binder ratio, GGBFS can be incorporated as high volume cement replacement. For instance, similar compressive strength/carbon footprint ratio can be obtained for blend B6 (60\% GGBFS, water/binder ratio $=0.65)$ compared to blend A3 $(30 \%$ GGBFS, water/binder ratio $=0.45)$, provided that the minimum 28 day compressive strength requirement is fulfilled for the former. The use of high amount of cement replacement material was also suggested by Kurad et al. [27] to improve the compressive strength/carbon footprint ratio.

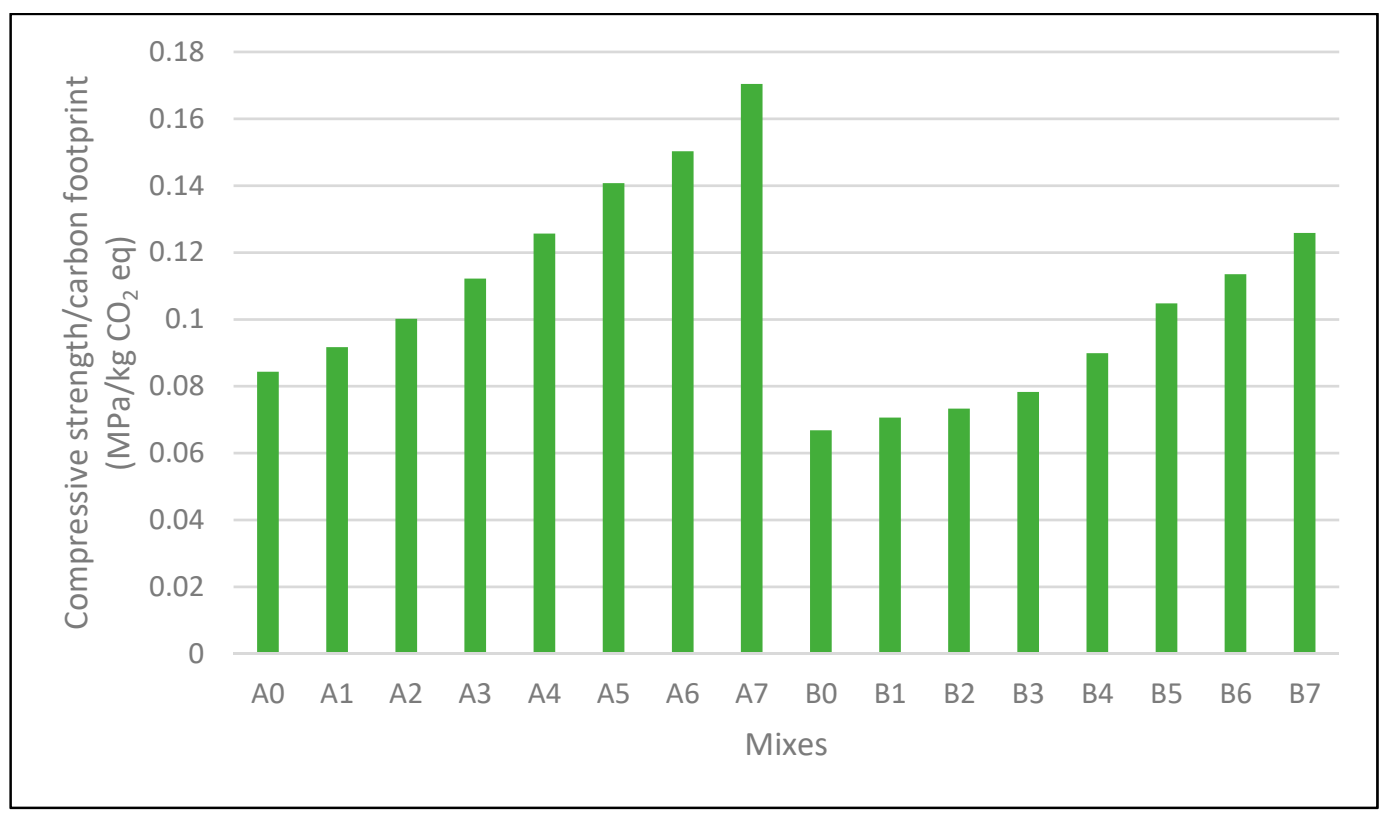

Figure 14. Compressive strength/carbon footprint ratios.

\subsection{Cost Efficiency}

While the use of GGBFS is found to be particularly effective in reducing the GWP of the studied blends, it is also important to consider the raw materials cost implications of the blends. For this purpose, the cost efficiency for each blend will be computed based on the compressive strength/materials cost per $\mathrm{m}^{3}$ ratio. The higher ratio indicates that greater compressive strength can be achieved with a lower materials cost. The cost of materials is based on the current market price in Malaysia. The market price of ordinary Portland cement is 240 MYR/tonne while the price of GGBFS is $200 \mathrm{MYR} /$ tonne. The price for mining sand is taken as $35 \mathrm{MYR} /$ tonne while the price of water is not taken into consideration since it is relatively low compared to the other materials. Table 6 below gives the computed compressive strength/materials cost per cubic meter of the mortar blends. 
Table 6. Cost efficiency of mortar blends.

\begin{tabular}{|c|c|c|c|}
\hline Blend & Cost $/ \mathrm{m}^{3}$ (MYR) & $\begin{array}{l}28 \text { Day Compressive } \\
\text { Strength (Mpa) }\end{array}$ & $\begin{array}{l}\text { Cost Efficiency } \\
\left(\mathrm{MPa} / \mathrm{MYR} \mathrm{m}^{-3}\right)\end{array}$ \\
\hline A0 & 184.20 & 48.41 & 0.2628 \\
\hline A1 & 182.04 & 47.87 & 0.2630 \\
\hline $\mathrm{A} 2$ & 179.88 & 46.98 & 0.2612 \\
\hline A3 & 177.72 & 46.78 & 0.2632 \\
\hline $\mathrm{A} 4$ & 175.56 & 45.86 & 0.2612 \\
\hline A5 & 173.40 & 43.92 & 0.2533 \\
\hline A6 & 171.24 & 39.07 & 0.2281 \\
\hline A7 & 169.08 & 35.61 & 0.2106 \\
\hline B0 & 174.05 & 38.29 & 0.2200 \\
\hline B1 & 171.89 & 36.80 & 0.2141 \\
\hline B2 & 169.73 & 34.36 & 0.2024 \\
\hline B3 & 167.57 & 32.56 & 0.1943 \\
\hline B4 & 165.41 & 32.71 & 0.1977 \\
\hline B5 & 163.25 & 32.70 & 0.2003 \\
\hline B6 & 161.09 & 29.39 & 0.1824 \\
\hline B7 & 158.93 & 26.05 & 0.1639 \\
\hline
\end{tabular}

When comparing the blends with a different water/binder ratio, as expected, the strength efficiency was higher for the A-series blends with lower water/binder ratio, since the binder content was fixed to be the same for both series and it is the binder materials which contribute to larger portion of the overall material cost. In terms of the effect of GGBFS, it can be seen that although the cost of GGBFS is lower than that of cement, inclusion of the former resulted in compressive strength reduction. Nevertheless, for both series of mixes, it is apparent that the inclusion of up to 50\% GGBFS as cement replacement is acceptable in terms of the cost efficiency whereby these blends demonstrated similar efficiency. On the other hand, further GGBFS replacement level would lead to greater influence of the compressive strength decrease compared to the cost reduction, hence decreasing the cost efficiency of these blends.

\section{Conclusions}

The study demonstrated that the overall carbon footprint of concrete can be reduced almost linearly by up to $63 \%$ with an increasing amount of GGBFS (up to $70 \%$ cement replacement) in the mix designs, thus producing sustainable concrete without compromising the performance whilst significantly reducing the negative environmental impacts incurred in its production. Generally, it is suggested that the higher cement replacement level with GGBFS of up to $70 \%$ will give better compressive strength/carbon footprint ratio whereas cement replacement with up to 50\% GGBFS is recommended when cost efficiency is considered. Therefore, overall, it is recommended that up to $50 \%$ GGBFS can be utilized in cement blends by taking into account the strength performance, carbon footprint and cost considerations. In addition, in terms of the influence of the water/binder ratio, when the binder content is kept constant, blends with lower water/binder ratio demonstrated better overall performance.

Author Contributions: C.C.O. and K.H.M. designed the research and written the manuscript. M.K.H.R. and W.H.L. performed the experiments, collected data and conducted the life cycle assessment. C.G.N. and S.Y. provided advice for the research and contributed in the life cycle assessment.

Funding: The financial support provided by University of Malaya under the funding Top100pdioes and RU013-2017A is gratefully acknowledged.

Conflicts of Interest: The authors declare no conflict of interest. 


\section{References}

1. Crossin, E. The greenhouse gas implications of using ground granulated blast furnace slag as a cement substitute. J. Clean. Prod. 2015, 95, 101-108. [CrossRef]

2. Miller, S.A.; Horvath, A.; Monteiro, P.J.M.; Ostertag, C.P. Greenhouse gas emissions from concrete can be reduced by using mix proportions, geometric aspects, and age as design. Environ. Res. Lett. 2015, 10, 114017. [CrossRef]

3. Li, G.; Zhao, X. Properties of concrete incorporating fly ash and ground granulated blast-furnace slag. Cem. Concr. Compos. 2003, 25, 293-299. [CrossRef]

4. Higgins, D. Briefing: GGBS and sustainability. Proc. Inst. Civ. Eng. Constr. Mater. 2007, 160, 99-101. [CrossRef]

5. Beushausen, H.; Alexander, M.; Ballim, Y. Early-age properties, strength development and heat of hydration of concrete containing various South African slags at different replacement ratios. Constr. Build. Mater. 2012, 29, 533-540. [CrossRef]

6. Siddique, R.; Bennacer, R. Use of iron and steel industry by-products (GGBS) in cement paste and mortar. Res. Conserv. Recyc. 2012, 69, 29-34. [CrossRef]

7. Ling, T.-C.; Poon, C.-S. Feasible use of large volumes of GGBS in 100\% recycled glass architectural mortar. Cem. Concr. Compos. 2014, 53, 350-356. [CrossRef]

8. Mo, K.H.; Alengaram, U.J.; Jumaat, M.Z.; Liu, M.Y.J. Contribution of acrylic fibre addition and ground granulated blast furnace slag on the properties of lightweight concrete. Constr. Build. Mater. 2015, 95, 686-695. [CrossRef]

9. Hannesson, G.; Kuder, K.; Shogren, R.; Lehman, D. The influence of high volume of fly ash and slag on the compressive strength of self-consolidating concrete. Constr. Build. Mater. 2012, 30, 161-168. [CrossRef]

10. Chao-Lung, H.; Anh-Tuan, B.L.; Chun-Tsun, C. Effect of rice husk ash on the strength and durability characteristics of concrete. Constr. Build. Mater. 2011, 25, 3768-3772. [CrossRef]

11. Mo, K.H.; Mohd Anor, F.A.; Alengaram, U.J.; Jumaat, M.Z.; Rao, K.J. Properties of metakaolin-blended oil palm shell lightweight concrete. Eur. J. Env. Civ. Eng. 2018, 22, 852-868. [CrossRef]

12. Muller, H.S.; Haist, M.; Vogel, M. Assessment of the sustainability potential of concrete and concrete structures considering their environmental impact, performance and lifetime. Constr. Build. Mater. 2014, 67, 321-337. [CrossRef]

13. Zhang, Y.; Zhang, J.; Luo, W.; Wang, J.; Shi, J.; Zhang, H.; Wang, Y. Effect of compressive strength and chloride diffusion on life cycle $\mathrm{CO}_{2}$ assessment of concrete containing supplementary cementitious materials. J. Clean. Prod. 2019, 218, 450-458. [CrossRef]

14. Onn, C.C.; Yusoff, S. The formulation of life cycle impact assessment framework for Malaysia using Eco-indicator. Int. J. LCA 2010, 15, 985-993. [CrossRef]

15. Babu, K.G.; Kumar, V.S.R. Efficiency of GGBS in concrete. Cem. Concr. Res. 2000, 30, 1031-1036. [CrossRef]

16. Samad, S.; Shah, A.; Limbachiya, M. Strength development characteristics of concrete produced with blended cement using ground granulated blast furnace slag (GGBS) under various curing conditions. Sadhana 2017, 42, 1203-1213. [CrossRef]

17. Mo, K.H.; Alengaram, U.J.; Jumaat, M.Z. Utilization of ground granulated blast furnace slag as partial cement replacement in lightweight oil palm shell concrete. Mater. Struct. 2015, 48, 2545-2556. [CrossRef]

18. Kim, T.; Tae, S.; Chae, S.U. Analysis of Environmental Impact for Concrete Using LCA by Varying the Recycling Components, the Compressive Strength and the Admixture Material Mixing. Sustainability 2016, 8, 389. [CrossRef]

19. Miller, S.A.; Monteiro, P.J.M.; Ostertag, C.P.; Horvath, A. Concrete mixture proportioning for desired strength and reduced global warming potential. Constr. Build. Mater. 2016, 128, 410-421. [CrossRef]

20. Tait, M.W.; Cheung, W.M. A comparative cradle-to-gate life cycle assessment of three concrete mix designs. Int. J. LCA 2016, 21, 847-860. [CrossRef]

21. Choong, J.E.; Onn, C.C.; Yusoff, S.; Mohd, N.S. Life Cycle Assessment of Waste-to-Energy: Energy Recovery from Wood Waste in Malaysia. Pol. J. Environ. Stud. 2019, 28, 2593-2602. [CrossRef]

22. Huijbregts, M.A.J.; Steinmann, Z.J.N.; Elshout, P.M.F.; Stam, G.; Verones, F.; Vieira, M.; Zijp, M.; Hollander, A.; van Zelm, R. ReCiPe2016: A harmonised life cycle impact assessment method at midpoint and endpoint level. Int. J. Life Cycle Assess. 2017, 22, 138-147. [CrossRef]

23. Zhou, X.; Slater, J.R.; Wavell, S.E.; Oladiran, O. Effects of PFA and GGBS on early-ages engineering properties of Portland cement systems. J. Adv. Concr. Tech. 2012, 10, 74-85. [CrossRef]

24. Gholampour, A.; Ozbakkaloglu, T. Performance of sustainable concretes containing very high volume Class-F fly ash and ground granulated blast furnace slag. J. Clean. Prod. 2017, 162, 1407-1417. [CrossRef] 
25. Mehmeti, A.; Angelis-Dimakis, A.; Arampatzis, G.; McPhail, S.J.; Ulgiati, S. Life Cycle Assessment and Water Footprint of Hydrogen Production Methods: From Conventional to Emerging Technologies. Environments 2018, 5, 24. [CrossRef]

26. Sameer, H.; Weber, V.; Mostert, C.; Bringezu, S.; Fehling, E.; Wetzel, A. Environmental Assessment of Ultra-High-Performance Concrete Using Carbon, Material, and Water Footprint. Materials 2019, 12, 851. [CrossRef]

27. Kurad, R.; Silvestre, J.D.; de Brito, J.; Ahmed, H. Effect of incorporation of high volume or recycled concrete aggregates and fly ash on the strength and global warming potential of concrete. J. Clean. Prod. 2017, 166, 485-502. [CrossRef]

(C) 2019 by the authors. Licensee MDPI, Basel, Switzerland. This article is an open access article distributed under the terms and conditions of the Creative Commons Attribution (CC BY) license (http://creativecommons.org/licenses/by/4.0/). 